\title{
Performance of the Final Year Medical Students - Universiti Malaysia Sabah in the End Surgical Senior Posting (SSP) Examination.
}

Basim AMHA ${ }^{\mathrm{a}}$ and Chee $\mathrm{FT}^{\mathrm{b}}$

${ }^{a}$ Department of Surgery, School of Medicine, ${ }^{b}$ School of Sustainable Agriculture, Universiti Malaysia Sabah

\begin{abstract}
Introduction: Assessment methods are used to provide students with both formal and informal feedback on their progress, and should be congruent with the objectives of the curriculum. To achieve this, it is necessary to bring the theories of learning and assessment together. Senior surgical posting is an intensive eight weeks attachment with overall surgical revision, provide an opportunity for the students to develop clinical skills, knowledge and attitudes, at it's end the students will be evaluated through three forms of assessment, their knowledge by MCQs, MEQs, and essay and their clinical skills by OSCE, short case and long case examination together with that there was continues assessment (log book and two handwritten case reports), the passing marks is 65 of 100, and passing the clinical section is mandatory. Materials and Methods: This paper studied the performance of final year (Year 5) medical students Universiti Malaysia Sabah (UMS)-school of medicine in the end senior surgical posting examination. Results and Conclusion: Through analysis of the data of their assessment results in this examination, it shows that the continuous assessment have strong effect on the final results of the students, and students have defect in theory back ground reflected by their poor MCQs performance, and the mode of UMS students learning is more towards deep approach.
\end{abstract}

KEYWORDS: Clinical-assessment, performance-assessment, senior surgical posting

Corresponding author;

Basim A. M. H. Almothafar

Department of Surgery, School of Medicine,

Universiti Malaysia Sabah

Locked Bag 2073, 88999 Kota Kinabalu, Sabah

e-mail: basim_amh@yahoo.com 